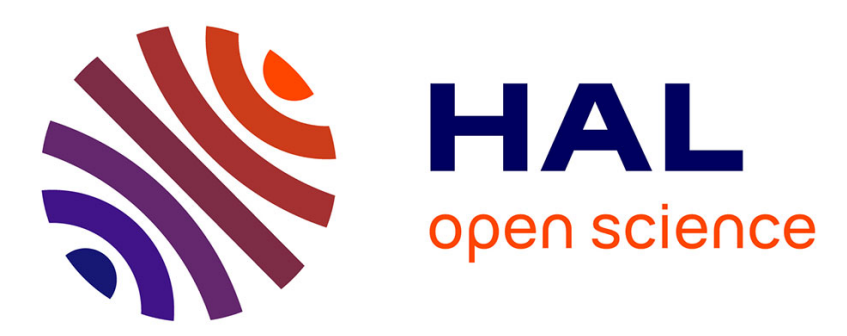

\title{
Transition to digital resources as a critical process in teachers' trajectories: the case of Anna's documentation work
}

Luc Trouche, Katiane Rocha, Ghislaine Gueudet, Birgit Pepin

\section{- To cite this version:}

Luc Trouche, Katiane Rocha, Ghislaine Gueudet, Birgit Pepin. Transition to digital resources as a critical process in teachers' trajectories: the case of Anna's documentation work. ZDM, 2020, 10.1007/s11858-020-01164-8 . hal-02647470

\section{HAL Id: hal-02647470 \\ https://hal.science/hal-02647470}

Submitted on 29 May 2020

HAL is a multi-disciplinary open access archive for the deposit and dissemination of scientific research documents, whether they are published or not. The documents may come from teaching and research institutions in France or abroad, or from public or private research centers.
L'archive ouverte pluridisciplinaire HAL, est destinée au dépôt et à la diffusion de documents scientifiques de niveau recherche, publiés ou non, émanant des établissements d'enseignement et de recherche français ou étrangers, des laboratoires publics ou privés. 


\section{Transition to digital resources as a critical process in teachers' trajectories: the case of Anna's documentation work}

Luc Trouche, Pr., Université de Lyon, ENS de Lyon, France, luc.trouche@ens-lyon.fr

Katiane Rocha, Dr., Centro Universitario Anhanguera de Campo Grande, Brazil mr.katiane@gmail.com

Ghislaine Gueudet, Pr., Université de Bretagne Occidentale, France, ghislaine.gueudet@inspebretagne.fr

Birgit Pepin, Pr., Technische Universiteit Eindhoven, The Netherlands, b.e.u.pepin@tue.nl

Abstract: In this paper we aim to contribute to a better understanding of the impact of digital resources on mathematics teachers' work and professional development. For this purpose we focus on the emblematic case of an experienced mathematics teacher at secondary level, Anna, who has also worked as a teacher educator in a university department. Using the lens of the Documentational Approach to Didactics (DAD), we investigate her case, with a particular interest in digital resources, including both digital curriculum resources (e.g., e-textbooks, online resources) and digital technologies (e.g., for communicating, sharing). Two notions appear essential for supporting this investigation: the notion of resource system for studying the teacher's activity as a whole, and the notion of documentational trajectory for studying the teacher's activity over the time. Methodologically, specific tools were developed for gaining deeper insights into the teacher's resource system, or her documentational trajectory. This study provides a window into mathematics teacher use and design of digital/non-digital resources in/for their teaching. Moreover, it helps us to develop better understandings of teacher professional learning over time, and of the ways the context of collaboration shapes their professional work and learning. More and also contrasting cases (e.g., of newly qualified teachers) would need to be studied to fully understand this field.

Keywords: digital resources; documentational approach to didactics; documentational trajectory; resource system; teachers' collective work; teachers' professional development. 


\section{Introduction}

As (educational) digital technology advances, education itself changes, and the nature of teachers' work changes with it in various venues, including the following: in the classroom (e.g., from instructor to facilitator); outside the classroom (e.g., lesson preparations); and with other teachers for collaborative work - in short, a whole metamorphosis of teachers' work emerges when working and teaching with digital technology. This is the focus of this article.

In this paper we aim to contribute new knowledge to the field of mathematics teachers' work with digital resources, by addressing selected themes proposed in this special issue, in particular the following: 'teacher professional development for digital resources use'; 'teacher use/design of digital resources tasks'; and 'communities of teachers working and learning collaboratively'. We do this by analyzing the case of a teacher, Anna: she started her career when the Internet began to disseminate web resources widely, and she has been strongly ${ }^{1}$ committed to sharing her work and resources with others via digital means.

The second section presents our theoretical framework and proposes the research questions. The third section sets the scene, by outlining the case study and the methodological tools for addressing the research questions. The fourth section reports on the results that cast light on these research questions. The fifth section discusses these results with respect to the themes of this special issue, and proposes perspectives for further research.

\section{The (digital) 'resource' approach to mathematics education}

In this section we first present the genesis of our theoretical frame, the Documentational Approach to Didactics (DAD), then the main concepts used in this study. Third, we draw on related research to discuss the concept of digital resources and associated terms. Fourth, we present our research questions.

\subsection{From technology to resources: the development of DAD}

The essence of DAD, developed since 2008 (Gueudet and Trouche 2009), is to consider teachers' work through their interactions with the resources of their teaching. It has been developed in a context of abundance of digital resources available for teachers. We present here essential sources of this approach, and the reasons justifying the need for new theoretical tools.

The presence of digital means in classrooms and its consequences have already been extensively studied in mathematics education research (e.g., Hoyles and Lagrange 2010). DAD draws on the instrumental approach (Artigue 2002, Guin et al. 2005), which has been developed and used for studying how students learn mathematics with technology. The instrumental approach distinguishes between an artefact and an instrument developed by the student, using this artefact for a specific aim of his/her activity (Verillon and Rabardel 1995). The instrument encompasses the artefact and an associated scheme of use (Vergnaud 1998). The process leading to the

\footnotetext{
${ }^{1}$ This adverb strongly has been chosen for characterizing a special feature of Anna's work, as she expresses herself: "I cannot work alone, I need really to design my lessons in interacting with colleagues, and the digital means make these interactions very easy to develop".
} 
development of an instrument is called the instrumental genesis. The research works using the instrumental approach to study classrooms equipped with digital means evolved progressively: while they initially focused only on students, the researchers started developing a joint interest in students and teachers. In this process new concepts were introduced as follows: e.g., the instrumental orchestration (Guin et al. 2005) considering how teachers manage students' instrumental geneses; or the double instrumental genesis for teachers (Haspekian 2014) evidencing that, along with their use of digital artefacts (e.g., a spreadsheet), teachers develop two instruments, namely, a personal instrument and a professional one.

But even considering the teachers' double instrumental genesis was not sufficient to grasp the deep evolutions that were instigated by the immensity of teaching resources available on the Internet, from lesson plans proposed by individual teachers to interactive exercises published by associations, for example. Moreover, defining what should be considered as a digital resource started to be complex: a lesson plan found on the Internet is certainly a resource. Should an email message received from a colleague be considered as a resource? These kinds of questions led us to work on the development of a new theoretical approach.

\subsection{Documentational geneses and documentational trajectory}

DAD (Trouche et al. 2018a) is grounded in an essential dialectic between resources and documents:

- Leaning on Adler (2000), in DAD we defined a resource as anything likely to 're-source' the teacher's practice. It can be a textbook or a website; it can also be a conversation with a colleague. Teachers search for resources, select resources and modify them; they use them in class, and this can lead to further modifications. In DAD this work is called teachers' documentation work. It can be individual or collective;

- Adhering to the instrumental approach, DAD considers that along this documentation work, for a specific aim of the activity, teachers develop a document, consisting of recombined resources, and a scheme of use for these resources. The construction of a document is called documentational genesis. In DAD, professional development is understood as the development of schemes, hence as documentational geneses.

The brief description above cannot account for the complexity of the distinction between resources, a notion at the heart of this paper, and documents. We add here some remarks, and elucidate terminology, in order to enlighten some important aspects of this complexity.

A scheme (Vergnaud 1998) is a stable organisation of the activity of a given subject for a given aim. This stability is reached along various situations corresponding to the same aim: a teacher meeting a new situation (characterized by a new aim) can mobilize and adjust existing schemes, or can develop a new scheme.

A document, developed from a set of resources, provides new resources: for example, for the aim 'teaching percentages at grade 8', a teacher using a lesson plan found on the Internet can develop a document. This document can contain a transformed lesson plan, adapted to her teaching context, and a scheme. The transformed lesson plan is also a resource. Hammoud (2012) has 
introduced the terms mother resource $(s)$ and daughter resource $(s)$ to distinguish between the resources (mother) involved in the birth of a document and the resources (daughter) resulting from its genesis. In the example above, the transformed lesson plan is a daughter resource. It can become a mother resource for the same teacher the following year (mother and daughter resources are not different levels, but different stages in the life of a resource). A daughter resource can be shared with colleagues; while the document itself cannot be shared, since a scheme is a personal construct encompassing unconscious elements that the teacher cannot communicate.

A given aim of activity characterizes a class of situations (Rabardel and Bourmaud 2005). For a given class of situations, the teacher develops a document. Classes of situations with a similar aim (for example, 'preparing and setting up an assessment') constitute an activity family (ibid.). Along his/her professional activity, a teacher develops a resource system, formed by all the resources s/he uses for this activity. When groups of teachers work collectively, they develop a shared resource system. We do not claim that they develop shared documents, as indeed the schemes are individual. Nevertheless elements of schemes can be the same for two teachers working together.

Rocha (2019) has introduced new concepts, in order to study documentation work over time:

- The teacher's documentational experience, drawing on the notion of experience defined by Pastré (2011), is defined as the accumulation and appropriation by a teacher of all her past documentational work. The teacher has a reflexive view on this past documentation work. We call documentational experience traits features explicated by a teacher as guiding her documentational work during a given period. For example, a teacher could say "at the beginning of my career, I was very attached to textbooks"; or "since 2015, I used social networks to have new ideas". These utterances correspond to 'traits': views entertained by the teacher about her documentation work during a given (past) period;

- An event is defined as something taking place in the teacher's professional environment and modifying her documentation work. For example, a change in the official curriculum, or a change of school, are events for a given teacher. The teacher's documentational trajectory is defined as a path (with continuities and ruptures) linking professional events (individual and/or collectives) lived by the teacher;

- The documentational dominant (dominant is used here as a noun) is a set of activity families orienting the teacher's documentation during a given period. For example, we can assume that at the beginning of teachers' careers the most important activity family, their documentational dominant, is 'preparing and setting up lessons'. We claim that the documentational trajectory of a teacher contains different successive periods, each of them characterized by a documentational dominant;

- A symbolic event of transition is defined as an event that generates a change in the documentational dominant, i.e., a change in the hierarchy of activity families for the teacher. This type of event is related to a rupture in teachers' documentation work, determining a 'before' and an 'after'. For example, the arrival in the school of a new 
colleague (experienced in differentiating her teaching) can radically change the importance of the activity family 'design and set up differentiated teaching'. Further examples are presented in our analyses.

Most research works using DAD keep a specific interest in digital resources. In this paper, the role of digital resources in the documentational trajectories are our central focus. The objective of the next section is to delineate what a digital resource is.

\subsection{From digital technologies to digital resources}

We justify in this section our choice of vocabulary, from digital technologies to digital resources. Concerning digital technologies, we distinguish between hardware (computers, tablets, calculator, or Interactive White Board) and software. Regarding software, we distinguish between mathematical software, like Dynamic Geometry Software; programming applications such as Python or Scratch; and organizing, sharing and communicating applications, which play a more and more important role. Among them, we distinguish the following:

- Applications allowing teachers to communicate or share resources as emails or platforms like Moodle, or social networks, like Twitter or Facebook;

- Applications allowing teachers to collect and sometimes to display students' productions, like Plickers or wireless networks (see, e.g., Hegedus and Moreno-Armella 2009);

- Institutional applications allowing teachers to communicate with parents (like Pronote in France for example);

- Digital curation tools like Pearltrees, digital curation being defined as intending to "transform teaching and learning through effective collection, categorization, critiquing, conceptualization, and circulation of resources" (Deschaine and Sharma 2015).

The consideration of digital technologies, in mathematics education, has largely evolved since the beginning of this century. The 17th ICMI study, entitled "Mathematics education and technology_rethinking the terrain" (Hoyles and Lagrange 2010), was a determining step in the acknowledgment of an evolution in the available technologies, and hence of a necessary evolution in the associated research. While the affordances and constraints of specific digital technologies were still studied, most researchers started considering the design of mathematics learning environments integrating technology. This does not only raise issues about the tools used, but also about the curriculum. So while the term 'digital technology' described a specific piece of software or a material tool, this digital technology was considered within an environment, incorporating in particular the mathematics curriculum (or part of it). Considering the possible future development of technological tools, Drijvers et al. (2010) emphasized the following: "Thinking about the evolution of ICT in education, the key expression that comes to the fore is connectivity" (ibid. p.121). These authors foresaw the Communication within ICT as the main place for future evolutions: possibilities of communication between students, between students and teachers (the potential for learning of these possibilities was already evidenced by Hegedus and Moreno-Armella 2009), between teachers, for which they coined the term 
'classroom connectivity'. This term evidences the need for focusing on the use of digital technologies by students and teachers, and especially the collective dimensions of this use.

We consider here all the diverse digital 'things' intervening in teachers' work, which we name digital resources. Among these digital resources, we distinguish two specific ones, which play an important role in teachers' practices, as follows:

- Open Educational Resources (OER) (Trouche et al. 2018b), which are defined by OECD (2007) as "digitized materials offered freely and openly for educators, students, and selflearners to use and reuse for teaching, learning, and research. OER includes learning content, software tools to develop, use, and distribute content, and implementation resources such as open licenses" (p. 10);

- Digital Curriculum Resources (DCR), which Pepin et al. (2017a) characterise in the following way: "it is the attention to sequencing - of grade-, or age-level learning topics, or of content associated with a particular course of study (e.g., algebra) —so as to cover (all or part of) a curriculum specification, which differentiates DCR from other types of digital instructional tools or educational software programs... Of course, DCR make use of these other types of tools and software: indeed, what differentiates them from predigital curriculum programs is that they are made accessible on electronic devices and that they often incorporate the dynamic features of digital technologies." (p. 647). DCR can be e-textbooks with organized content covering all the curriculum of one or several given levels etc.

After having situated our background, theoretically as well as practically, we now formulate our research questions.

\subsection{Research questions}

In this paper we claim that digital resources contribute to a metamorphosis of teachers' documentation work, and our aim is to deepen our understanding of this metamorphosis. More precisely, we study the following research questions:

1) What is the role of digital resources in teachers' resource systems, how are they combined with other resources, how do they shape the structure of the system?

2) What are the consequences of the interactions between teachers and digital resources in terms of teachers' documentational trajectories and professional development?

3) What are the consequences of the interactions between teachers' and digital resources in terms of teachers' collective work? How can collective work contribute to a productive use of digital resources by teachers?

We do not propose detailed analyses of Anna's documentational geneses, since our focus on the evolutions brought by digital resources leads us to prioritise the level of her whole career.

\section{Setting the scene of the case study}

We present the following in this section: first, the case of Anna; second, our methodological 
frame, the reflective investigation approach, linked to our theoretical perspective; third, our methodological choices for answering our research questions.

\subsection{The context of Anna's case}

Anna is a mid-career French mathematics teacher, working in a middle school (students from 11 to 15 years old) situated in the center of a big city. This school is associated with the French Institute of Education, providing teachers means for working together, meeting researchers, and comparing their experiences with teachers of other associated schools in France. Anna is involved in various contexts of interacting with resources, both as a user and a designer. She is also an advanced teacher, taking on different roles: part time as a teacher in her school; part time as a teacher educator, welcoming beginning teachers into her class, or monitoring teacher training sessions; and part time as a research assistant in the French Institute of Education. She appears to be then a real multiplier (Rösken-Winter et al. 2015). Anna started her career at the beginning of this century, and developed it over the same period as digitalization of learning and teaching environments became prominent. Anna, as a teacher strongly interacting with resources and colleagues, provides us a privileged window for analyzing what 'teaching with digital resources' means. Analyzing an advanced case may give relevant information on promising practices and interesting phenomena suitable for study.

Anna is strongly engaged in a variety of collectives: in her school, coordinating the team of mathematics teachers; in the French mathematics teacher association (APMEP), acting as board member; in the Institute of Research on Mathematics Teaching (IREM), a place where mathematics teachers from pre-primary school to higher education can reflect and work together (Trouche 2016); and in Sésames, a small team, gathering for ten years a researcher and some teachers, to rethink the teaching of Algebra (Alves et al. 2013). This collective appeared particularly productive, developing the following: (1) a website: Pegame (http://pegame.enslyon.fr/), for disseminating its resources; (2) models of resources like Warm Up Model (WUM, Mise en train in French), stimulating students' engagement at the beginning of a lesson by giving them an intriguing question. In these different collectives, Anna works in close collaboration with her colleague Cindy.

In September 2016, the French mathematics teachers faced a curriculum change (Gueudet et al. 2017), integrating a new topic to be taught: algorithmics. Teachers had then to design new resources, giving the researchers a window for looking at teachers' resource systems, and at their evolution.

\subsection{The reflective investigation methodology}

The DAD methodology is based on the five principles of reflective investigation (Trouche et al. 2018a): (1) a broad collection of the material resources used and produced by the teacher; (2) a long-term follow-up; (3) an in- and out-of-class follow-up; (4) a reflective follow-up of the teacher's documentation work; and (5) a permanent confrontation of the teacher's views on her documentation work with the materiality of this work. All these principles stem from the DAD 
holistic view on a teacher's work, taking into account her interactions with all the resources nourishing her teaching.

For applying these principles, the active involvement of the teacher is a practical necessity, as $\mathrm{s} / \mathrm{he}$ is the one having access, over time and space, to her documentation work (beyond the direct observation of the researcher). Practically, the reflective investigation combines direct observation of the teacher's documentation work - the preparation, implementation and evaluation of a lesson are privileged occasions for doing that - and indirect observation of this work, in soliciting the teacher's view on her current documentation work, in addition to the teacher's recollections of her previous work.

Regarding her current documentation work, different tools were designed, for example a reflective box where Anna stored the successive versions of the resources she designed for her class, and the mapping of Anna's resource system, with two sides (Rocha 2019):

- A reflective mapping of resource system (RMRS), in line with the reflective investigation, where Anna is asked to represent herself the different components of her resource system, associated with the different activities they are used for;

- An inferred mapping of resource system (IMRS), where the researcher infers, from the different collected data, a representation of the structure of a teacher resource system.

Each reflective mapping drawn by the teacher was transposed on a digital support system by the researcher (Figures $2 \& 3$ ). Each inferred mapping was drawn by the researcher, asking sometimes for the teacher's feedback for the purpose of correcting it. Then, when we evoke a reflective (vs. inferred) mapping of the teacher's resource system, it is the result of such a process. Finally, RMRS and IMRS are effectively a combination, with different relative contributions, of the teacher's view and the researcher's analysis.

Regarding Anna's previous documentation work, Rocha proposed, using the same dialectic perspectives, a reflective (vs. inferred) mapping of a teacher documentation trajectory (RMDT vs. IMDT). This map tries to capture changes in teachers' individual and collective work over time. Regarding more particularly teachers' collective work, we mobilized the methodological device proposed by Wang (2019) named documentation-working mates (DWM), which involves following two teachers working closely together, on a regular basis, for preparing their lessons (Figure 1). 


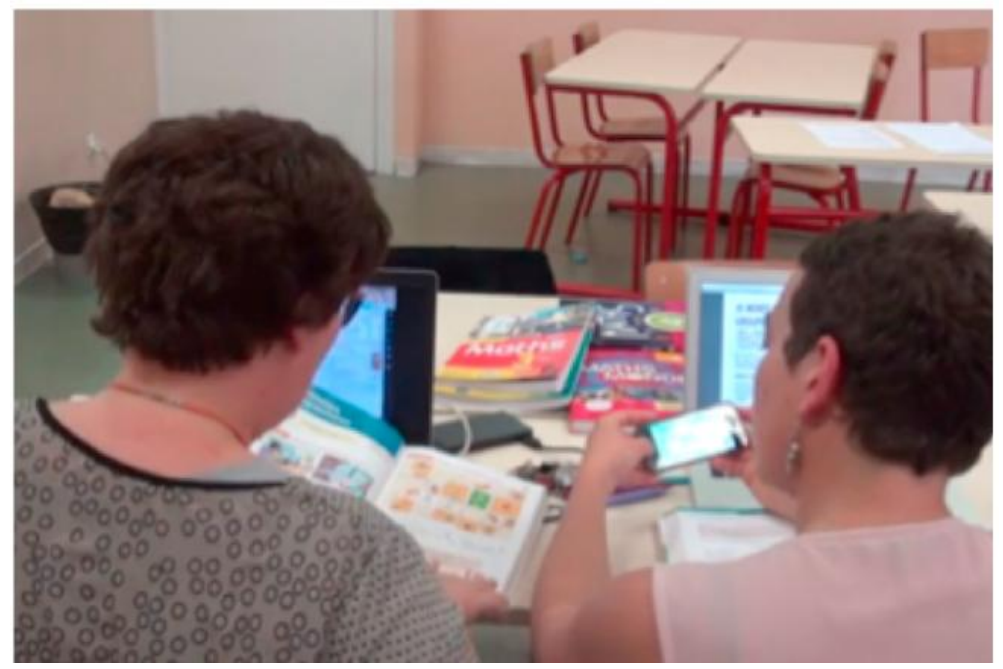

Fig. 1. Anna and Cindy preparing a lesson using both digital and paper resources (Trouche et al. 2019)

The researcher followed the interactions between this pair, and hence had access to richer and more natural interactions than those occurring when the researcher asked the teacher directly. This DWM environment offers a privileged context for addressing issues related to teachers' collective work with resources.

\subsection{Data analysis methodology}

For this paper, we use only a part of these data, mainly four interviews with Anna, and the observation of preparation of a lesson by Anna and Cindy (from 2016 to 2019). Of course, our analysis was enlightened by our knowledge of Anna's and Cindy's documentation work followup over time, e.g., the data coming from Anna' reflective box (Section 3.2). It is also noteworthy that the above mentioned French curriculum change (Section 3.1) happened during this period of data collection.

For the first question (Q1), related to the place of digital resources in Anna' resource system, we used mainly the data from interviews in which Anna designed her RMRS 1 describing the set of all her resources and her RMRS 2 focusing on her own digital resources. Following Hammoud (2012), we analyzed these mappings with respect to four points: (1) the grouping terms, analyzing the - explicit or implicit - categorization of resources; (2) the general structure of the mapping, looking for some-implicit or explicit-hierarchy; (3) the absolute position of terms (center, highlight, etc...); and (4) the relative position of terms, analyzing the presence of resources influencing the design of other resources. For each mapping, we confronted the results of our analysis with the results of our own direct observation of Anna's documentation work. Lastly, we compared the results coming from the analysis of RMRS 1 and RMRS 2 for answering Q1.

For the second question (Q2), related to documentational trajectory and Anna's professional development, we used mainly the data coming from interviews in which she designed her RMDT or revised it. Specially, we asked Anna to situate the successive integration of her main digital resources on a timeline, using it to obtain an inferred mapping of Anna's documentation 
trajectory dedicated to digital resources (Figure 4). Based on these data, we inferred symbolic events of transition, documentational experience traits and documentational dominant (Section 2.2). Among all the events evoked by Anna, we identified, symbolic events of transition with respect to three criteria: these must (1) have opened new opportunities for professional development; (2) have led to renewing Anna's resource system; (3) arrived in a year in which many events happened, evidencing a concentration of new opportunities. Then we questioned an eventual change of documentational dominant, in crossing each symbolic event of transition, in analyzing the documentational experience traits before and after this event.

For the third question (Q3), related to Anna's collective work, we mainly used the episode of Anna's collective work with Cindy, her DWM, when preparing a new lesson. This episode appears as emblematic, as the two teachers had to plan a lesson on a (for them) totally new topic, algorithmics. On such an occasion, Anna and Cindy had to confront the following: to make sense of what content really needs to be taught; and to find new resources for reaching their teaching objectives. We focus here on the role of digital resources for supporting this work, and on the role of collective work for a productive use of digital resources.

In the following section, we describe the application of this methodology.

\section{The findings: scrutiny of a metamorphosis}

In this section, we present our findings. First, we consider Anna's resource system, and the way digital resources are shaping it (Section 4.1). Second, we consider Anna's documentational trajectory, looking at the development of her resource system over time, and the way digital resources are shaping its development (Section 4.2). Third, we analyze the way digital resources support and shape Anna's collaborative work with her documentation-working mate Cindy (Section 4.3).

\subsection{The place of digital resources in Anna's resource system}

In this section we report on the analyses of the two interviews (and drawings) to help answer the first research question. In the first step, we analyse RMRS 1 produced by Anna in 2017 to map the whole collection of her resources (Figure 2). 

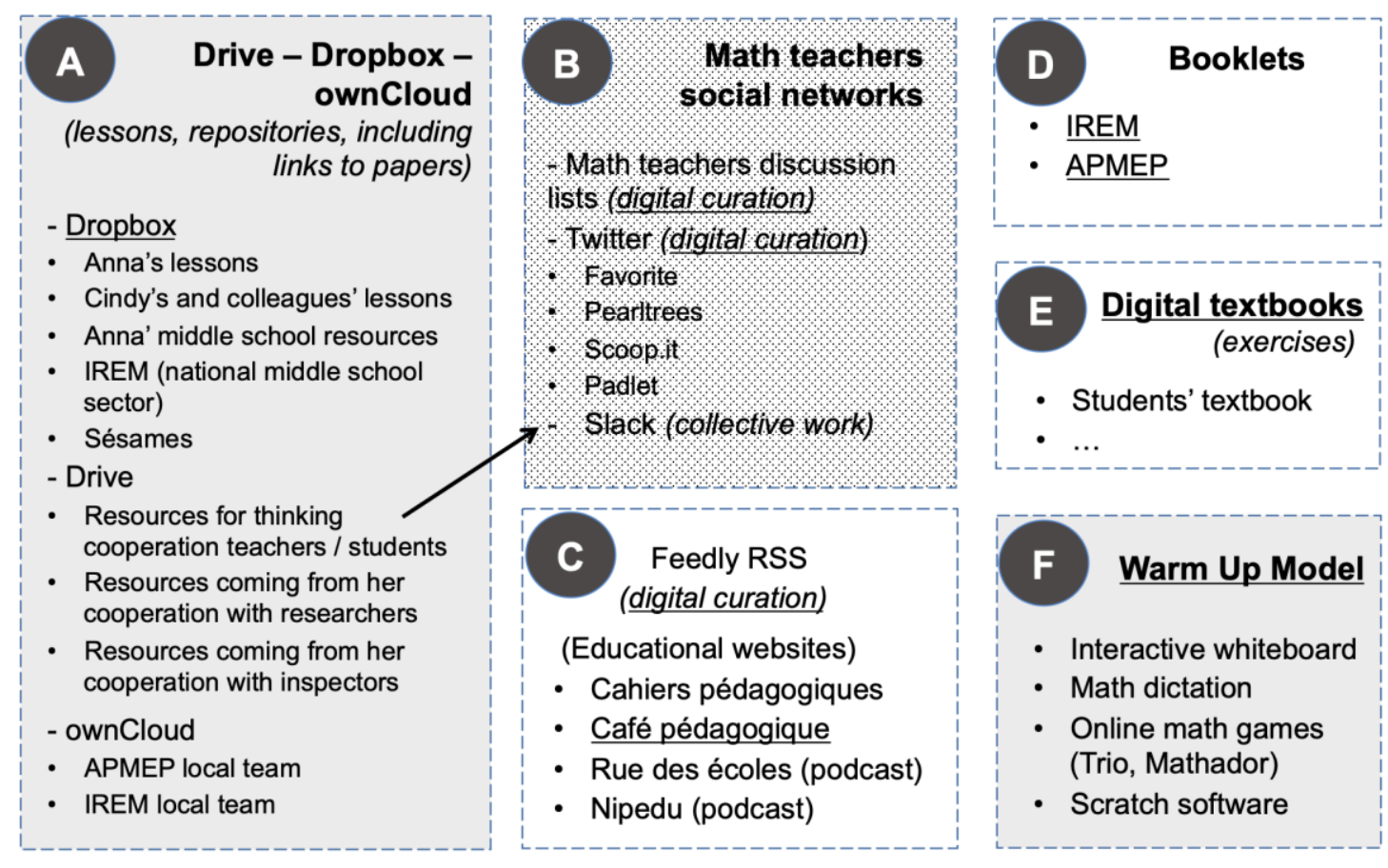

Fig. 2. Anna's RMRS 1 (June 2017)

We analyzed RMRS 1 following our methodology, as follows:

- First, we inferred six categories (grouping and letters resulting from our choices): (A) daughter resources stored and shared in the cloud, designed by herself, by the collectives she is part of, and by close colleagues; (F) daughter resources following Warm Up Model, resulting from the Sésame experience; (B) mother resources coming from digital curation on social networks; (C) mother resources coming from digital curation on educational websites; (D) mother resources coming from APMEP and IREM paper booklets; and (E) mother resources, particularly for designing exercises, coming from digital textbooks;

- Second, Anna structured her mapping with respect to the place of resources in the process of documentation work (mother resources vs. daughter resources) and with respect to their location (in the cloud vs. in her computer);

- Third, regarding the absolute position of the terms, we have to note that Anna underlined IREM and APMEP booklets, Warm Up Model, and digital curation. IREM and APMEP booklets, products of the experience of these teachers' in the network, the only non digital resources in RMRS 1, constitute an efficient didactical support for teaching specific mathematical notions, a kind of 'bible', for following Anna's wording. Warm Up Model provides a model for designing other resources, helping her to introduce new notions (Rocha 2019). For digital curation (appearing three times in RMRS 1) Anna developed a coordinated system on her laptop, work computer and smartphone (for example, she mobilized diverse applications for managing new information arising from the follow-up, using Twitter, or websites dedicated to education);

- Fourth, regarding the relative position of terms, one arrow is particularly interesting, 
namely, linking resources for thinking cooperation teachers/students and Slack. During the interview, Anna emphasised that one of her major interests at this time was to learn more about stimulating students' cooperation in class. Thanks to Twitter, she discovered CoopMaths, a French website dedicated to students' cooperative work. She started to cooperate with the team of teachers contributing to this website, and discovered, in the thread of this cooperation, a platform giving a new means (chat, co-design, storage) for collaborating, named Slack (https://slack.com).

RMRS 1, even if it was not focusing on digital resources, provides interesting information on the role of digital resources in Anna's documentation work. We retain here four main results:

- Most of Anna's and her colleagues' daughter resources are digital, and in the cloud (category A). That means that they can share and access them everywhere: at home, when participating in various collectives, or in their classroom;

- All the digital resources that she uses, or has designed, are OERs;

- Digital curriculum resources came from different sources: from the cooperation with colleagues, researchers or inspectors (category A), from the mathematics teachers' discussion list (category B), from educational websites (category C) and/or from digital textbooks (category D);

- The collectives play an essential role for Anna' documentation work, namely, the collectives she is part of, as well as the collectives providing her with resources, particularly through the process of digital curation.

Two years later Anna produced RMRS 2, where she focussed on digital resources. 


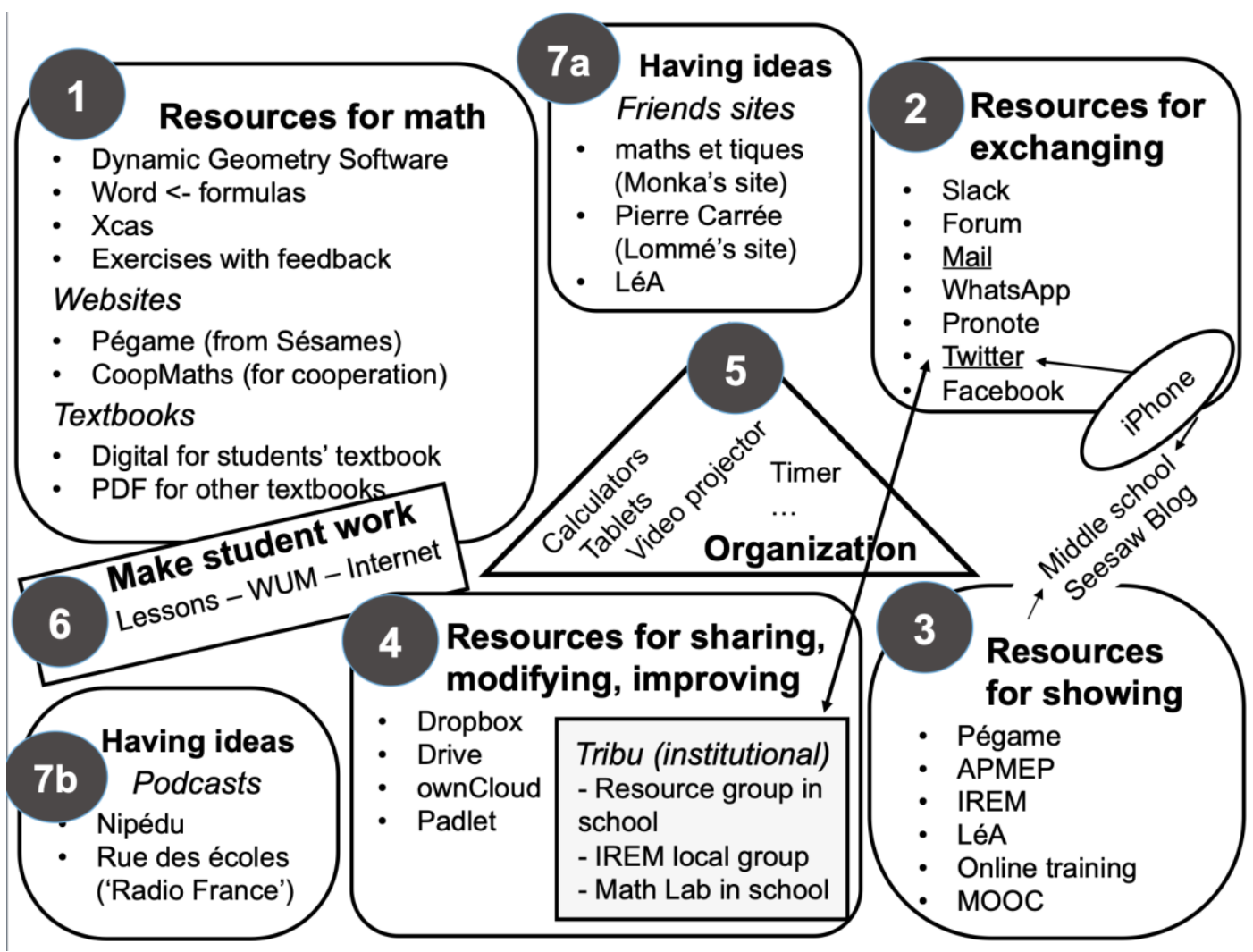

Fig. 3. Anna's RMRS 2 (May 2019) focusing on her digital resources

In addition to these two elements (date and focus), we have to take into account a third difference from the conditions of RMRS 1: we had also asked Anna to propose a categorization of her digital resources. Hence, the 7 categories structuring RMRS 2 (Figure 3) were her own classifications:

- First, Anna proposed seven categories (numbered following the order of their appearing): (1) Resources for mathematics contains digital technologies, websites supporting her main collective work, and textbooks; (2) Resources for exchanging contains tools for communicating (Pronote is the institutional application for communicating with school staff, parents and students) and social networking; (3) Resources for showing contains websites for accessing and disseminating resources for/from various collectives, including teacher education; (4) Resources for sharing, modifying, improving contains resources for working in the cloud, including a subcategory dedicated to co-designing in school (see below); (5) Organization contains a set of digital technologies dedicated to managing classroom orchestration (§1.3); (6) Make student work contains tools, lessons and models for designing lessons (Warm Up Model) dedicated to spurring students' activity; and (7a and 7b) Having ideas (written in two parts due to the remaining free space on the paper sheet) contains resources for digital curation, on one side via institutional websites, on the other via teachers' websites;

- Second, Anna structured RMRS with respect to the structure of her activity, i.e., the different types of situations of her documentation work, with the organization of her 
classroom activity at the center, reinforced by the category 6 Make the student work. Both on the top and on the left side, the category 7 Having ideas appears as essential for feeding her work;

- Third, Anna circled two terms: First, the institutional workspace, provided by the French Ministry of Education, named Tribu (Tribe in English, can be used to store resources, create collaborative groups and chat, see more in https://tribu.phm.education.gouv.fr/); second, her mobile, which she uses a lot, because most of the interfaces that she uses can be opened on it;

- Fourth, she uses arrows for underlining two critical interactions. First, she linked Tribu and Twitter, which she uses in combination for supporting discussions with her colleagues; second, she uses (in a combined way) Twitter, mobile and middle school Seesaw blog (Seesaw is dedicated to meaningfully engaging students in their learning, see https://web.seesaw.me/blogs).

RMRS 2 provides new information on the role of digital resources in Anna's documentation work:

- Even if RMRS 2 does not aim to map all Anna's resources - only the digital ones are targeted - it seems to encompass her main resources. Compared to RMRS 1, we miss only the APMEP and IREM booklets (which actually are now provided digitally);

- Thinking digital resources leads Anna to be much more complete about drawing her resources; actually, in RMRS 1, thinking only resources was perhaps not clear to her and she forgot all the digital technologies as parts of her resource system (software as well as resources used for orchestrating mathematics classrooms);

- Anna mapped her digital resource system by following the structure of her activity; we may infer that her own activity is structured by her digital resources;

- Finally, there is no category purely dedicated to design; design appears as a combination of sharing, modifying and improving. Design appears to be mostly re-design.

\subsection{The role of digital resources for configuring Anna's documentational trajectory}

We address this issue first by inferring the main components of Anna's documentational trajectory, and second, by integrating the digital resources over time.

Over the whole of Anna's career (1994 to 2019), we can infer two symbolic events of transition (i.e., satisfying three criteria, see 2.3): Starting membership in Sésames, in 2006, and starting a half time position in IFÉ in 2013. We have then three periods to examine, for inferring documentational dominants:

- From 1994 to 2006,: we extracted different documentational experience traits, as "at the beginning of my career it was hard for me to get involved in collective work in order to produce resources", or "at the beginning of my career I created my resources using existing resources in order to save time", therefore we named the corresponding documentational dominant as Designing resources; 
- From 2006 to 2013: we identified huge changes in her documentational work. She said "It was a big change, still. The fact to accept, well, to want to... to accept to go to Sesames. I never asked myself before”. In this collective she created many resources leading her to rethink the teaching of Algebra (Rocha 2019). We infer several documentational experience traits, e.g., "From the moment when I entered Sésames, I started to be more interested in Algebra teaching"; and "In Sésames I discovered participatory action-research as a means for thinking how to improve my teaching". Thus, we claim that the documentational dominant was Reflecting and renewing resources. It is noteworthy that Anna met her documentation-working mate Cindy during this period;

- From 2013 to 2019, having a half time position in IFE led Anna to be more involved in different projects, particularly related to teacher education using Sésames resources. We highlight here three documentational experience traits: "Today, my lessons are quite stable, then their renewing goes very smoothly"; "Today I develop a digital curation on several sites to get more resource ideas for my lessons"; and "Today I use in a regular way social networks for disseminating my practices, my resources and my questioning”. Thus we claimed that the documentation dominant, in this period, was Refining and disseminating resources.

This analysis provides us with the structure of Anna's documentational trajectory (Figure 4). During these two interviews, even if the focus was not on digital resources, we collected abundant information about Anna's use of digital resources. In order to complement the information, we asked Anna to describe the successive integration of digital resources, over her career, with respect to the seven categories she had herself proposed (Figure 3). And finally we pasted her answers under the structure of her documentational trajectory for obtaining what we called her IMDT focusing on digital resources (Figure 4). 


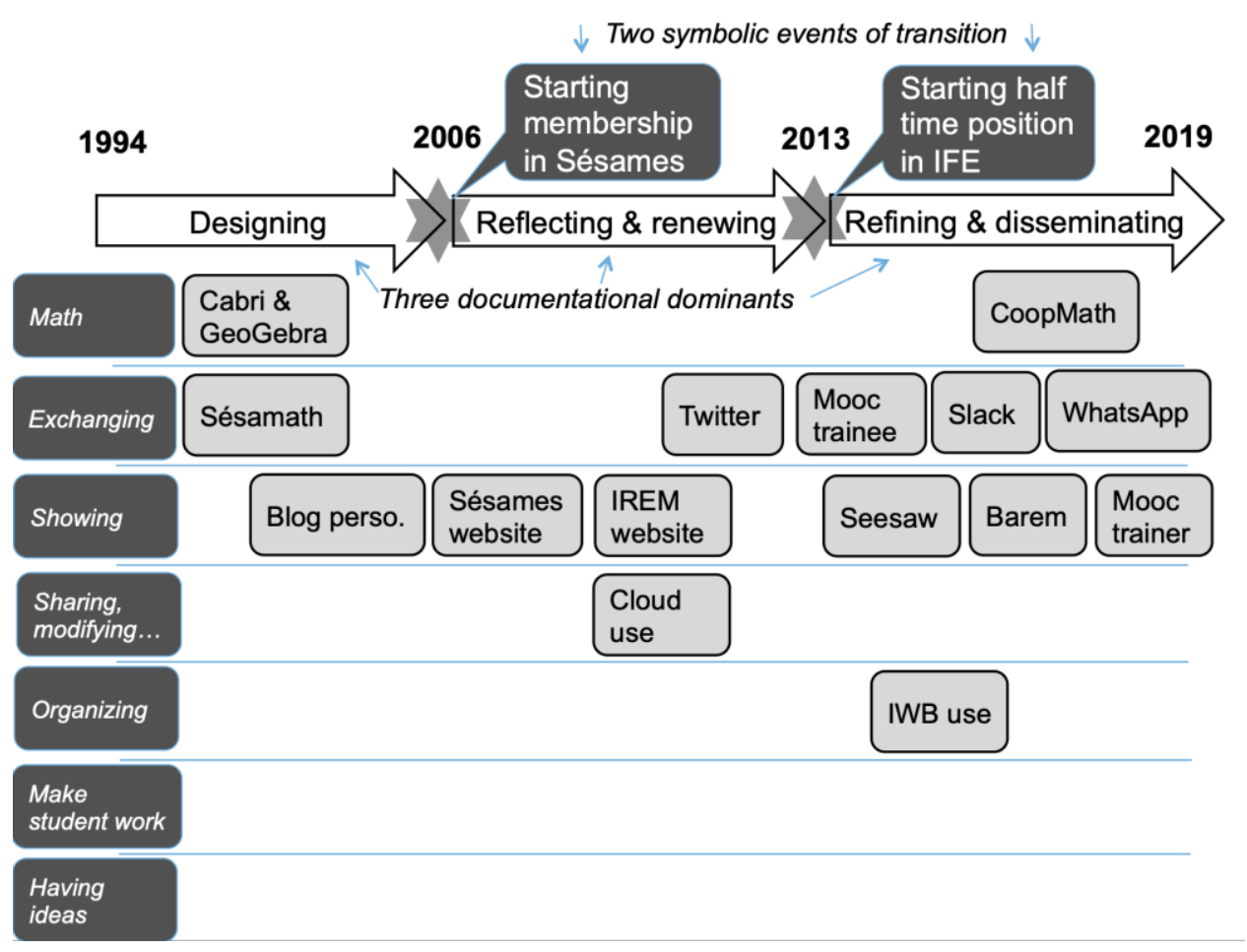

Fig. 4. Anna's IMDT(May 2019) focusing on digital events/resources, with respect to 7 categories (Section 4.1) nothing for categories 6 and 7

Following our solicitation, Anna retained only what appeared at this moment to be her main digital resources. That could explain that nothing was produced in terms of the 6th and 7th categories: making student work, as well as digital curation, are permanent components of her documentation work. It is clear that the three periods of her documentation work are also three contrasting periods regarding the integration of digital resources:

- In the first period (Designing), digital resources started to be used by Anna with respect to three categories: to teach mathematics using dynamic geometry software; to exchange, via Sésamath, the first French platform, designed by a teacher association, designing collaboratively and providing free online textbooks; and to show her information using personal blogs;

- In the second period (Reflecting and renewing), her integration in Sésames led her to join different collectives, and to actively participate in the development of their websites. She discovered Twitter, and a fourth category of activity (Sharing, modifying, improving) was implicated via the intensive use of the Cloud (Drive, Dropbox and ownCloud);

- In the last period (Refining and disseminating), digital resources marked all the aspects of Anna's documentation work, from the work in her classes (Organizing), with the intensive use of an IWB (allowing her to use her resources stored on the cloud) to the development of Resources for Math, with the implication in CoopMath (both a community and a platform providing tools for cooperation). After having developed, in the first period, a personal blog, she developed now a blog with her students (Seesaw). In 
a dynamic of professional development, she moved from the position of Mooc trainee to the position of Mooc trainer. She discovered and used new applications (the last one was WhatsApp). It is noteworthy that she used a new institutional platform, BaREM (https://www.barem-hatier.fr/), financed by the ministry of education and freely accessible to teachers and students for four years but developed by a private publisher.

We have analyzed Anna's usage of digital resources mainly from what she self-reported, and from what her resources showed. In the following section, we analyse an episode of Anna's documentation work itself, in order to gain access to her actual documentation work.

\subsection{The role of digital resources for supporting Anna's collective work}

The two previous sections evidence how digital resources can support collective work in different ways, e.g., by organizing work, exchanging resources, designing together, disseminating resources, having a common space to save resources, among others. In this section we analyze teachers' collective interaction with resources in action, benefitting from the opportunity of a national curriculum change (Section 3.1). We observed Anna and Cindy preparing together the progression for teaching algorithmics, a totally new topic for them, for grade 5. As we reported in another publication (Trouche et al. 2019), we have already analyzed this episode through different theoretical lenses. We focus here, through the DAD lens, on the role of digital resources for supporting Anna's and Cindy's collective work, presenting first the way we collected the data, then the way we analysed them, and finally answering our third research question.

In May 2016, Anna and Cindy decided to plan together their 'algorithmics' teaching for the coming semester, and accepted the presence of a researcher, who would video-record this situation. They had attended short training sessions on this new topic, which were organized by the mathematics inspectors, mainly dedicated to the use of the software Scratch. They were asked to bring with them all the available curriculum materials they could mobilize for preparing this teaching - and they finally brought a diversity of such materials, including textbooks (13 different ones), IREM booklets, official curriculum documents, their personal laptops containing their digital resources including the links that they normally used for preparing their lessons. Anna had prepared a Padlet, projected on an IWB, gathering a set of resources coming from her digital curation. This preparation situation happened in Anna and Cindy's middle school (Figure 5), in a mathematics classroom where they typically did their regular collective interaction with resources. It is noteworthy that Anna and Cindy brought a set of paper textbooks that had been produced for supporting the implementation of the new curricular topic area. Even if Anna said that she used no more paper textbooks, they still remained as a background to her documentation work: in such a situation where they had to face a new curriculum, they felt the need to have the books easily available, and that they could 'flick through easily' (Figure 5, left). Hence, the textbooks represented the 'voice of the curriculum' for them. 

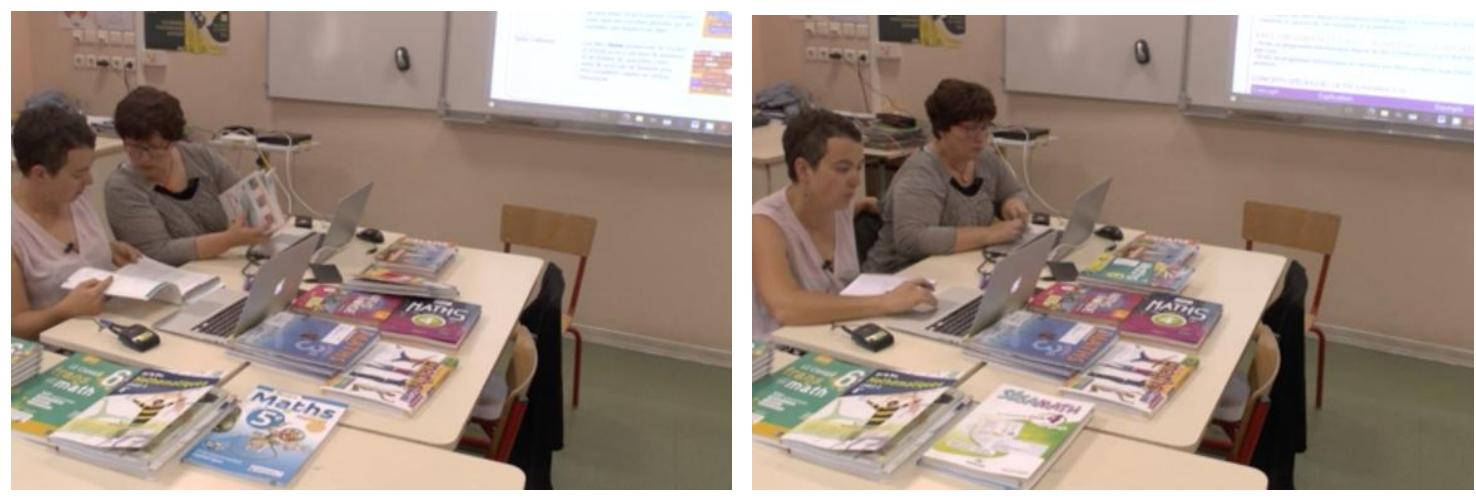

Fig. 5. Anna and Cindy' collective work using both paper textbooks and digital resources

For analyzing teachers' work, we set up a timeline model (Figure 6), aiming to design a script of the session, which involved the following components: distinguishing significant/important issues the teachers were facing, the answers they proposed, and the moments where these answers occurred; determining successive significant stages of the two teachers' documentation work; and analyzing how these stages, answers and moments could be explained from the point of view of digital resources.

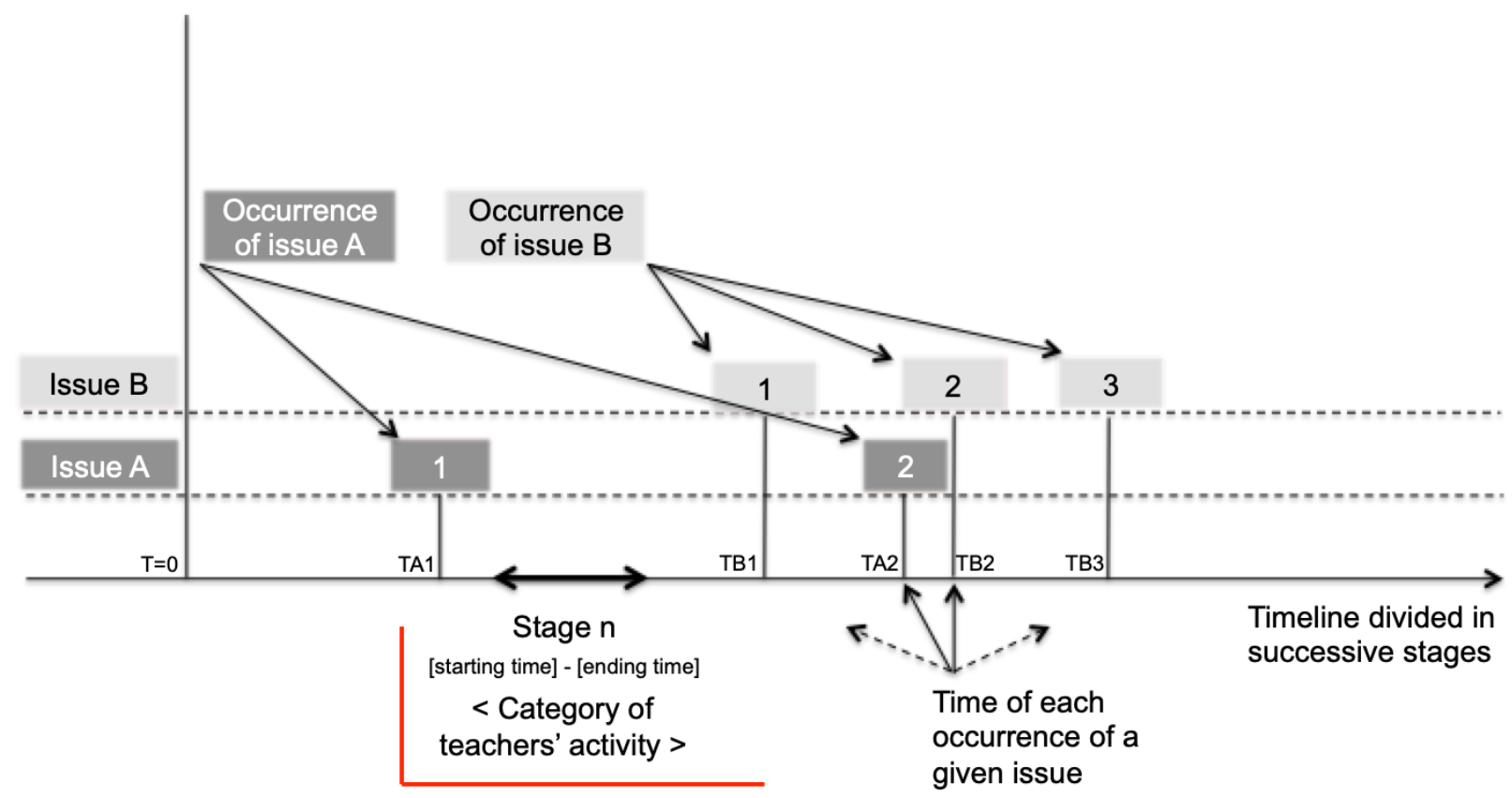

Fig. 6. Model for supporting our analysis of Anna and Cindy documentation work

Selected main results are presented in Figure 7. 


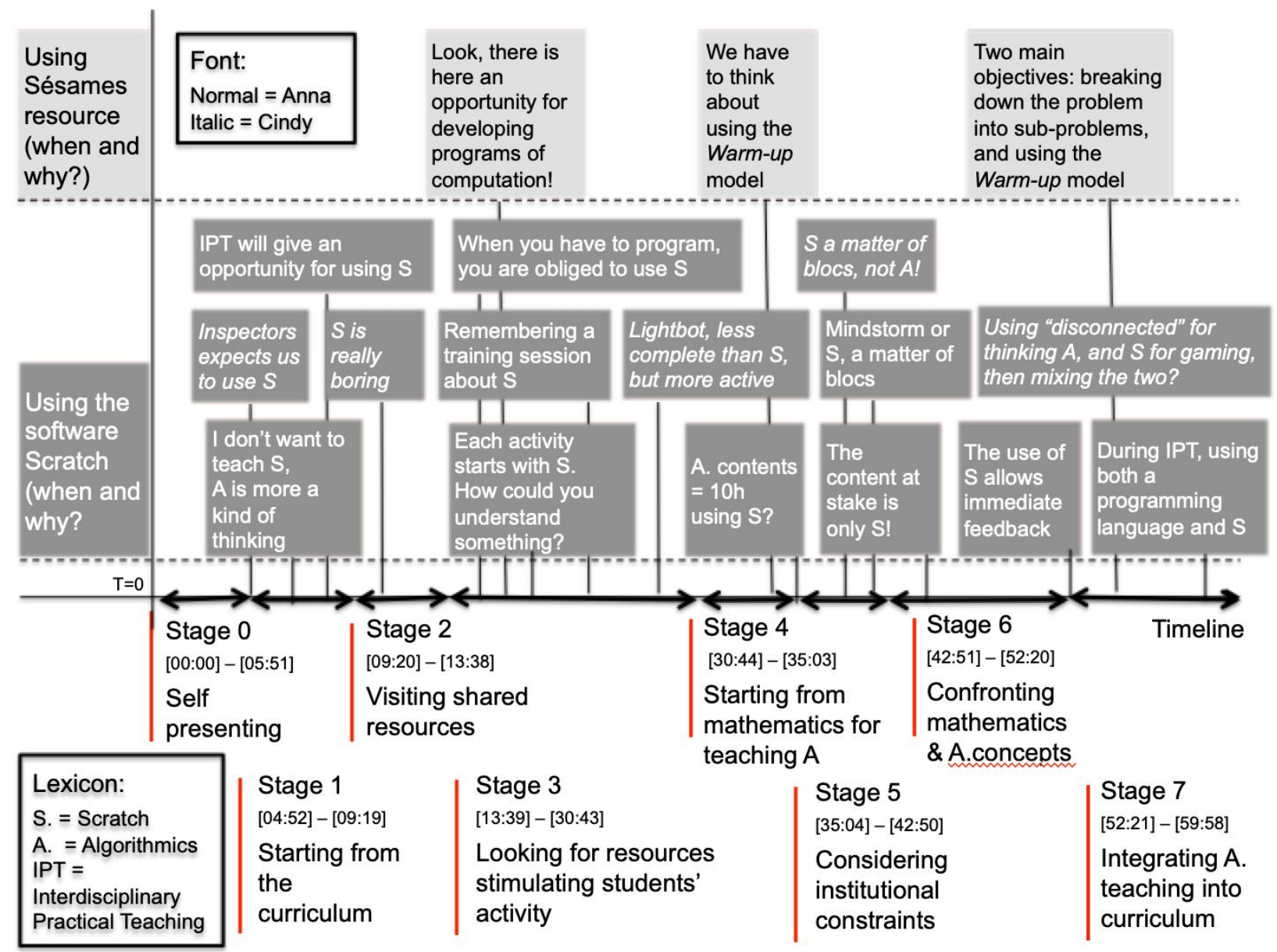

Fig. 7. Stages, issues and moments of Anna's and Cindy's collective work with resources

Over the time of their collaborative work we could distinguish seven stages:

(1) Looking at the curriculum description, which was stored in Anna' middle school resources, a Dropbox folder shared by the team of math teachers of the school (Figure 2). This was a typical digital curriculum resource that Anna had not evoked directly in describing her available resources.

(2) Visiting shared well known resources, essentially in the Dropbox folder (Figure 2) containing Anna's and Cindy' personal resources, the middle school mathematics teachers shared resources, and the Sésames resources, looking for resources that could be adapted to the new topic.

(3) Looking for new resources, in line with the new curriculum, with respect to an essential condition, namely, stimulating students' activity. In this longest stage of this documentation work, Anna and Cindy looked alternatively at their collection of paper textbooks and at some specific websites recommended by the inspectors, by the collective they are part of (particularly IREM), and sometimes by the textbooks themselves. For examining digital resources, they used alternatively their computers, or their mobile phones. 
(4) and (5) Using the springs of their resource systems, both from a content point of view (the organisation of mathematics knowledge) and from a practical one (the Warm Up Model, as a generator of new resources), they reflected on a possible integration of the new topic with respect to the existing equilibrium of their teaching;

(6) This activity led them to confront the mathematics 'spirit' and the algorithmics 'spirit' from an epistemological point of view (for example concerning the respective meanings of the notion of 'variable');

(7) In the last stage, they imagined a way of introducing algorithmics in balancing unplugged activities (paper and pencil activities) and Scratch activities.

We retain two main issues (left side of Figure 7), namely, the way they could benefit from the Sésames resources, and the way they could integrate Scratch in a productive way. We can now understand better why, in Figure 2 (category F), designed in May 2017 (year of the implementation of the new curriculum), Anna underlined the Warm Up Model, and Scratch (the only software mentioned in this mapping). Warm Up, as a meta-resource giving a frame for supporting the design of a new resource, was particularly precious in these circumstances; and Scratch ( $S$ in Figure 6 ) was conceived by the institution ('the inspectors') as an essential means for implementing algorithmics teaching ( $A$ in Figure 6).

\section{From the metamorphosis of the teaching environment to the metamorphosis of teachers' documentation work}

In this section we first answer the three research questions, before identifying implications of this research for theory and practice, situating it within the frame of the questions posed in this ZDM special issue.

\subsection{Answering the three research questions as articulated issues}

(1) What is the role of digital resources in teachers' resource systems, how are they combined with other resources, and how do they shape the structure of the system?

The structure of Anna's resource system relates mostly to the structure of her 'digital resource' system, and this structure seems to be closely linked to the structure of Anna's documentation work. Digitalization strongly shapes both Anna's resource system and Anna's activity:

- A new family of activity appears, digital curation, mostly via the Internet, and seems to be critical for feeding Anna's resource system;

- Sharing, modifying and improving appear to be completely interrelated, leading to redesign rather than designing from scratch, and to a new equilibrium between individual and collective work with resources;

- Most of the resources are OERs, shared and stored in the cloud, available and modifiable from everywhere by all associated authors;

- Digitalization leads to both a bigger diversification and a bigger connection of resources, thanks to the Internet, to specific digital tools (particularly smartphones), to specific 
platforms, and to social networks.

By comparing RMRS 1 and RMRS 2 and identifying differences between the two, we note that this metamorphosis of Anna's resource system developed indeed over time. Hence, we claim that it is necessary to take time into account, which is the purpose of the following section.

(2) What are the consequences of the interactions between teachers and digital resources in terms of teachers' documentational trajectories and professional development?

The mapping of Anna's resources (see Figure 4) illustrates what we could describe as the joint dynamics of digital resource usage and teacher professional development. Each new stage of Anna's professional development goes with the integration of new digital resources. The following points are noteworthy:

- First, to consider the evolution of these resources themselves in terms of integration: during the first period (Figure 4), Anna evoked three kinds of digital resources having different separate functions (software, textbook, and blog). During the last period, each resource evoked had different integrated functions (such as CoopMath, or Twitter allowing her to meet new online collectives and new resources to use with her students);

- Second, taking a closer look at the function of 'channel of professional development' of digital resources and associated communities, we note that Anna started as a trainee in a Mooc, participated in collaborative projects, as member, then as coordinator, and subsequently became a trainer in this Mooc. The development of applications dedicated to classroom blogs led her to move from having a personal blog to co-designing a blog with her students.

(3) What are the consequences of the interactions between teachers' and digital resources in terms of teachers' collective work? How can collective work contribute to a productive use of digital resources by teachers?

In the case of Anna and Cindy, we claim, first, that the digital technologies (e.g., computer, mobile, cloud) played an essential role in spurring these teachers' collective work with resources, not only during their practical work 'on the spot', but also over time, providing the means for constituting a shared collective resource system, whose analysis should require further analysis. Second, the digital curriculum resources (mostly OER, freely available) opened up space for renewing these teachers' resource systems. Third, the face-to-face interactions between the two teachers, facing a complex issue, led them to critically analyse possible contributions to the available resources, and the discussion about Scratch appears as emblematic in this respect.

\subsection{Implications for theory and practice in mathematics education}

For the purpose of answering our three research questions, we took three different perspectives, namely, the analysis of teachers' resource systems, the analysis of their documentational trajectories, and the analysis of an episode of their documentational work. We claim that these perspectives are necessary for understanding both the deep changes produced by the digitalization of teachers' work, and the elements of continuity in teachers' work. In terms of this 
Special Issue, we contend that we have contributed to the illumination of the following aspects: mathematics teachers' (re-)design and use of resources (with our analysis of a teacher's resource system); mathematics teachers' professional trajectories (with the analysis of Anna's documentational trajectory); and mathematics teacher (potential) learning in collectives (with the analysis of the episode of Anna and Cindy).

These analyses led us to more general considerations about the need for balancing digital and non-digital resources. Anna and Cindy interacted continuously (e.g., via Twitter or WhatsApp), but their face-to-face interactions appeared to have been necessary when complex issues needed to be tackled. They claimed that they used only digital resources, but, when they wanted to compare different textbooks, they continued to use their paper versions. They were aware of the potential of digital resources (e.g., IWB, Seesaw) to elicit students' cooperation, but they still developed hands-on activities (e.g., 'unplugged activities') in their preparations (Figure 7, right). They combined notes on their computer, and scribbled in a notebook. In our analyses of these combinations of digital and non-digital resources, we interpreted this activity, not as a temporary survival of the past, but as a necessary support of human development, joining the analysis of Maschietto and Soury-Lavergne (2017) on the combination of material and digital artifacts.

In terms of professional learning, we have seen that (1) curriculum change, in this case the change of the mathematics curriculum in France to include algorithmics, can be an inspiration for and initiation of more intense professional development activity. Teachers have to (re-)design their courses/lessons from scratch, and these design activities (alone or collectively) are likely to enhance their capacities (e.g., Pepin et al. 2017b). (2) It appears that professional learning is likely to be more beneficial in groups, or collectively, as teachers develop a common resource system that is sourced by several professional experiences and 'trajectories'. This is likely to enhance their complexity, and at the same time provide increased opportunities for the transformation of knowledge (Leufer et al. 2019).

In theoretical terms, we claim that the lens of resources and resource systems has helped us to develop deeper understandings not only of their use/design of digital or non-digital resources in/for their teaching, but also provided a window into the development of their professional learning over time, and the ways the context of collaboration shapes their professional work and learning. Moreover, the concept of documentational trajectory (and its associated data collection and analysis strategies) was particularly helpful in this respect.

\subsection{Limitations of the research}

There are clear limitations of the research. First, in this paper we have chosen to investigate one teacher (Anna) and her collaborative activities with one other teacher (Cindy). This was a deliberate choice, as we wanted to delve into and investigate in depth their 'design' practices, in particular with digital resources, individually and collectively. We contend that this has highlighted issues that would have been difficult to identify, and in such 'density', had we investigated 100 teachers. At the same time we recognise the issue of generalisability with a study such as this one: we cannot claim that this context and the chosen teachers are typical for 
mathematics teachers, not even for mathematics teachers in France. Hence, the results we obtained from Anna and Cindy have to be considered in a particular context and linked to their particular situation: for example, the context of France in terms of curriculum change context; the particular working relationship between Anna and Cindy; their particular previous experiences; and their particular expertise in terms of digital curriculum resources.

Second, these particular circumstances also link to our results in terms of Anna's professional career, regarding pedagogy, professional institutions and her professional learning, and the mathematics - these are all linked, like a spider's web, and they come together in the person of Anna and her professional growth. Anna kept on being interested in 'new ideas' (e.g., algorithmics), which helped her to invite reforms as levers for personal change in terms of pedagogy (e.g., using digital resources in her learning environment) and of the mathematics (e.g., not to teach Scratch), and at the same time helped her professional career to move from 'ordinary mathematics teacher' to becoming a teacher educator (part-time), and hence mediating between an academic and a professional institution (school).

In spite of these limitations, we contend that Anna (and Cindy) were 'advanced teachers' (and Anna had become a multiplier over the years). This helps us, in the sense that these advanced teachers could provide 'promising scenarios' in terms of mathematics teachers interacting with digital resources, which highlights generalisable issues regarding the relationship of digital (curriculum) resources and teacher professional development/learning, individually or collectively.

\section{References}

Adler, J. (2000). Conceptualising resources as a theme for teacher education, Journal of Mathematics Teacher Education, 3, 205-224.

Alves, C., Coppé, S., Duval, V., Goislard, A., Kuhman, H., Martin Dametto, S., PioltiLamorthe, C., \& Roubin, S. (2013). Utilisation des programmes de calcul pour introduire l'algèbre au collège. Repères-IREM, 92, 9-30.

Artigue, M. (2002). Learning mathematics in a CAS environment: The genesis of a reflection about instrumentation and the dialectics between technical and conceptual work. International journal of computers for mathematical learning, 7(3), 245.

Deschaine, M., \& Sharma, S.A. (2015). The Five Cs of digital curation: Supporting twenty-first century teaching and learning. InSight: A Journal of Scholarly Teaching, 10, 19-24, https://eric.ed.gov/?id=EJ1074044

Drijvers, P., Kieran, C., \& Mariotti, M.-A. (2010). Integrating technology into mathematics education: Theoretical perspectives. In C. Hoyles \& J.-B. Lagrange (Eds.). Mathematics education and technology-Rethinking the terrain. The 17th ICMI Study (pp. 89131). New York: Springer.

Gueudet, G., Bueno-Ravel, L., Modeste, S., \& Trouche, L. (2017). Curriculum in France: A national frame in transition. In D. Thompson, M. A. Huntley, \& C. Suurtamm (Eds.), 
International Perspectives on Mathematics Curriculum (pp. 41-70). Charlotte, NC: International Age Publishing.

Gueudet, G., \& Trouche, L. (2009). Towards new documentation systems for teachers? Educational Studies in Mathematics, 71(3), 199-218.

Guin, D., Ruthven, K., \& Trouche, L. (Eds.) (2005). The didactical challenge of symbolic calculators: Turning a computational device into a mathematical instrument. New York: Springer.

Hammoud, R. (2012). Le travail collectif des professeurs en chimie comme levier pour la mise en cuvre de démarches d'investigation et le développement des connaissances professionnelles. Contribution au développement de l'approche documentaire du didactique. PhD thesis, Université Lyon 1 https://tel.archives-ouvertes.fr/tel-00762964

Haspekian, M (2014). Teachers' instrumental geneses when integrating spreadsheet software. In A. Clark-Wilson, O. Robutti, \& N. Sinclair (Eds.), Them mathematics teacher in the digital era (pp. 241-275). New York: Springer.

Hegedus, S. J., \& Moreno-Armella, L. (2009). Intersecting representation and communication infrastructures. ZDM Mathematics Education, 41(4), 399-412.

Hoyles, C., \& Lagrange, J.-B. (Eds.) (2010). Mathematics education and technologyRethinking the terrain. The 17th ICMI Study. New York: Springer.

Leufer, N., Prediger, S., Mahns, P., \& Kortenkamp, U. (2019). Facilitators' adaptation practices of curriculum material resources for professional development courses. International Journal of STEM Education, 6(24), https://doi.org/10.1186/s40594-019-0117-0

Maschietto, M., \& Soury-Lavergne, S. (2017). The duo 'pascaline and e-pascaline': An example of using material and digital artefacts at primary school. In F. Ferrara, A. Montone, \& E. Faggiano (Eds.) Innovation and technology (pp. 137-160). Cham: Springer.

OECD (2007). Giving knowledge for free. The emergence of open educational resources. Paris: OECD.

Pastré, P. (2011). La didactique professionnelle. Approche anthropologique du développement chez les adultes. Paris : Presses universitaires de France.

Pepin, B., Choppin, J., Ruthven, K, \& Sinclair, N. (2017a). Digital curriculum resources in mathematics education: Foundations for change. ZDM Mathematics Education, 49, 645-661. Doi: 10.1007/s11858-017-0879-z

Pepin, B., Gueudet, G., \& Trouche, L. (2017b). Refining teacher design capacity: Mathematics teachers' interactions with digital curriculum resources. ZDM Mathematics Education, 49(5), 799-812, http://rdcu.be/tmXb

Rabardel, P., \& Bourmaud, G. (2005). Instruments et systèmes d'instruments, in P. Rabardel, \& P. Pastré (dir.), Modèles du sujet pour la conception. Dialectiques activités développement (pp. 211-229). Toulouse: Octarès. 
Rocha, K. (2019). Une étude des effets du travail documentaire et collectif sur le développement professionnel des enseignants de mathématiques: Apport des concepts d'expérience et de trajectoire documentaires. Ph.D. thesis, Ecole normale supérieure de Lyon, France. https://tel.archives-ouvertes.fr/tel-02399664/

Rösken-Winter, B., Schüler, S., Stahnke, R. \& Blömeke, S. (2015). Effective CPD on a large scale: examining the development of multipliers. ZDM Mathematics Education, 47(1), 1325.

Trouche, L. (2016). Didactics of mathematics: Concepts, roots, interactions and dynamics from France. In J. Monaghan, L. Trouche, \& J. Borwein. Mathematics and tools, instruments for learning (pp. 219-256). New York, NY: Springer

Trouche, L., Gitirana, V., Miyakawa, T., Pepin, B., \& Wang, C. (2019). Studying mathematics teachers' interactions with curriculum materials through different lenses: Towards a deeper understanding of the processes at stake. International Journal of Educational Research, 93, 53-67, retrieved on May $21^{\text {st }} 2019$ from https://doi.org/10.1016/j.ijer.2018.09.002

Trouche, L., Gueudet, G., \& Pepin, B. (2018a). Documentational approach to didactics. In S. Lerman (Ed.), Encyclopedia of mathematics education. N.Y.: Springer. Doi: 10.1007/9783-319-77487-9_100011-1

Trouche, L., Gueudet, G., \& Pepin, B. (2018b). Open educational resources: A chance for opening mathematics teachers' resource systems? In L. Fan, L. Trouche, C. Qi, S. Rezat, \& J. Visnovska (Eds.), Research on mathematics textbooks and teachers' resources: Advances and issues (pp. 3-27). Cham: Springer

Vergnaud, G. (1998). Toward a cognitive theory of practice. In A. Sierpinska \& J. Kilpatrick (Eds.), Mathematics education as a research domain: A search for identity (pp. 227241). Dordrecht: Kluwer Academic Publishers.

Verillon, P., \& Rabardel, P. (1995). Cognition and artifacts: A contribution to the study of though in relation to instrumented activity. European journal of psychology of education, 77101.

Wang, C. (2019). An investigation of mathematics teachers' documentation expertise and its development in collectives: Two contrasting cases in China and France. Ph.D. thesis, Ecole normale supérieure de Lyon (France) and ECNU, Shanghai (China), https://tel.archivesouvertes.fr/tel-02275820. 